\title{
Creating local management legitimacy
}

\author{
Evelyn Pinkerton $^{\mathrm{a}, *}$, Leonard John ${ }^{\mathrm{b}, 1}$

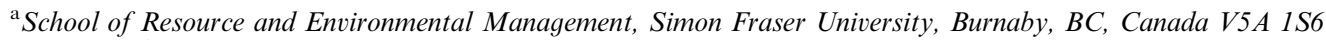 \\ ${ }^{\mathrm{b}}$ Kyuquot/Checleseht Fisheries, Kyuquot/Checleseht First Nations, Kyuquot, BC, Canada
}

Received 5 November 2007; received in revised form 3 December 2007; accepted 15 December 2007

\begin{abstract}
How can legitimate local management be created in a situation initially lacking respect for both local authority and federal government regulations? This question is addressed through examination of the 18-year history of what became an effective local regulatory regime for clams in an aboriginal community in British Columbia, Canada. After considering structural conditions favoring local management in the fishery, the community, and governance arrangements, four stages in the development of legitimate local management are examined, considering the roles of regulatory, scientific, political, and moral legitimacy. Eight hypotheses regarding the larger question of legitimate fisheries regulations are confirmed or proposed.
\end{abstract}

(C) 2007 Elsevier Ltd. All rights reserved.

Keywords: Co-management; Legitimacy; Shellfish management; TURFs; Ecological knowledge

\section{Introduction. Why study legitimacy?}

Because it is generally agreed that fishing systems need to be sustainable, reasonably efficient, and effective, fisheries management is increasingly thought of as a three-legged stool requiring contributions from ecologists, economists, and other social scientists [1]. But there has been little agreement among these three disciplines about why monitoring and enforcement of fishing regulations is such a major problem, absorbing considerable resources in most fisheries. In some high-value fisheries, government agencies have abandoned hope of achieving voluntary compliance with regulations through conventional means and have adopted systems of on-board observers or 24-h camera surveillance, in addition to dockside and in-plant monitoring. These actions have imposed significant costs on fishers (and in some fisheries simply eliminated small-scale producers). In many other fisheries, such methods are either not logistically possible or cannot be achieved economically, so the search for more effective approaches continues [2].

\footnotetext{
*Corresponding author. Tel.: + 17787824912 ; fax:1 7787824968.

E-mail address: epinkert@sfu.ca (E. Pinkerton).

${ }^{1}$ Tel.: + 12503380474 .
}

Some economists have argued that property rights-based systems increase compliance or even eliminate the need for investment in enforcement, because self-interest will create a self-enforcing regime. However, many quota systems which were originally claimed to be self-enforcing are being found to have non-compliance problems or high enforcement costs [3]. Some are even among those now requiring costly camera surveillance. So it is encouraging that some economists ([4], see Hatcher et al. of Ref.[3]) see benefit in looking at the legitimacy of regulations (and even the fisheries system), which other social scientists have long held to play a major role in compliance. These scholars argue that to use power effectively, gain acceptance of, and compliance with, social policies and regulations, authorities need to obtain legitimacy [5]. These authors would likely consider camera surveillance as evidence of low to non-existent legitimacy, equivalent to treating fishers like prison inmates [6].

Ecologists have added an interesting twist to this equation. Schumann [7] found that compliance was higher when Chilean fishers had developed "consciousness" about the ecology of an area through their respectful relationship with ecologists who conducted stock assessments for and with their local management group, sharing ecological findings with fishers when the latter were interested in 
taking training with them. It is an important finding that the sharing of ecological knowledge by natural scientists can play a key role in legitimizing regulations, even when these regulations are created by a local management authority. Co-management scholarship has documented many cases in which fishers' knowledge contributed to natural science, but there has been less emphasis on what natural science contributed to fishers' knowledge, or how natural science could legitimize co-management or local management. Exceptions to this pattern are discussed in depth in Soto [8], who highlights the discussions in two studies addressing this question. Gendron et al. [9] document a Quebec lobster fishery in which ecologists "contributed to the successful implementation of stronger conservation measures, to which fishers were very receptive...the fishers realized the impact of increased effort on the stocks." Zwanengburg et al. [10] document the effective relationships in the Nova Scotian Fishermen and Scientists Research Society between government scientists and fishers who collaborate with them on data collection, research, and interpretation of results, to the point of fishers sometimes designing the research. In both these situations, the sharing of natural science understandings of stock status and marine ecology contributed significantly to the legitimacy fishers accorded regulations based on these understandings.

The goal of this discussion is to contribute to an understanding of how fishing regulations become legitimate in the eyes of affected local fishers. What are the processes? What are the key dimensions of legitimacy? How do they interact?

\section{Methods}

These questions are approached by exploring a 18-year legitimacy-building process in one fishery in one community, Kyuquot (Fig. 1), which had key conditions in common with the Schumann case described above: (1) the management system is area-based and thus has many of the characteristics of a Territorial Use Rights Fishery or TURF [11] at least informally; (2) widespread poaching and disregard for regulations had been the norm in the past; (3) the area had been drastically overfished and closed, and some portions of it had to remain closed; (4) a local group of fishers became involved in making regulations; (5) scientific stock assessment played a key role in crafting the regulations, and fishers often participated voluntarily in the assessments; (6) the state fisheries agency did not play an active role in monitoring and enforcement.

It is unclear to what extent the findings of this study can generalize to fisheries or communities with structural characteristics different from the ones outlined above and in more detail in Section 4 below. It is likely, however, that many of the dynamics of legitimacy creation are universal. The goal here is therefore to suggest possibilities and generate hypotheses about some of the key dynamics and conditions which can be tested in future research.
In order to examine the development of legitimacy, this discussion analyzes the development of a local management system over 18 years and considers fishers' perceptions of: (a) the fishing regulations, (b) the management system, and (c) the management authority. It follows Tyler [12] in considering that both process and outcome dimensions of management are important: i.e., that to be considered legitimate, regulations must be perceived to be effectively and fairly enforced (process), and that the results (outcomes) of regulations are also perceived as effective and fair.

However, attention is also paid to the management system, conceptualizing management more broadly than simply the activity of regulating fishing activity during a fishery. A range of management rights that were successfully asserted on an informal basis by the local fisheries authority are identified, including the local regulation and enforcement of harvesting schedules, of internal access, of external exclusion, of habitat protection, and of stock data collection and analysis. These assertions of rights may be considered a good test case of the legitimacy of local authority, because these rights were asserted at the same time that the local authority enforced unpopular government regulations regarding non-harvest in areas believed by government to have water quality concerns. Building legitimacy thus faced an unusually steep uphill battle.

This unique opportunity for an in-depth historical analysis presented itself because the second author had served as head of the local fisheries program, Kyuquot/ Checleseht Fisheries (KCF), for a 20-year period, 1986-2006, between age 21 and 41. In this role he was the major player who initiated and stewarded the processes described below, learning as he went. In this paper he identified the key events which created change, and the major shifts in practice and consciousness over time, allowing the first author to generate analytical categories for conceptualizing these.

The first author lived in Kyuquot a total of nearly five months over a three-year period 2004-2006, conducting semi-structured interviews with 15 clam diggers, 10 band officials/staff, and 5 community leaders. She attended community meetings, read historical records from office files, worked with a local committee discussing how to enlarge the scope of clam co-management, participated in community events, and had multiple informal conversations with some $50 \%$ of the adult community residents. Outside the community, she interviewed federal and provincial regulatory officials, leaders in the Nuu-chahnulth Tribal Council (NTC), leaders and diggers in adjacent communities, attended four meetings of the West Coast Vancouver Island Clam Board [15] (which meets semi-annually) and eight meetings of the West Coast Vancouver Island Aquatic Management Board (which meets more frequently). ${ }^{2}$ These sources were used to verify,

\footnotetext{
${ }^{2}$ The West Coast of Vancouver Island (WCVI) Aquatic Management Board (AMB) was formed in 2002, following eight years of activism in the
} 


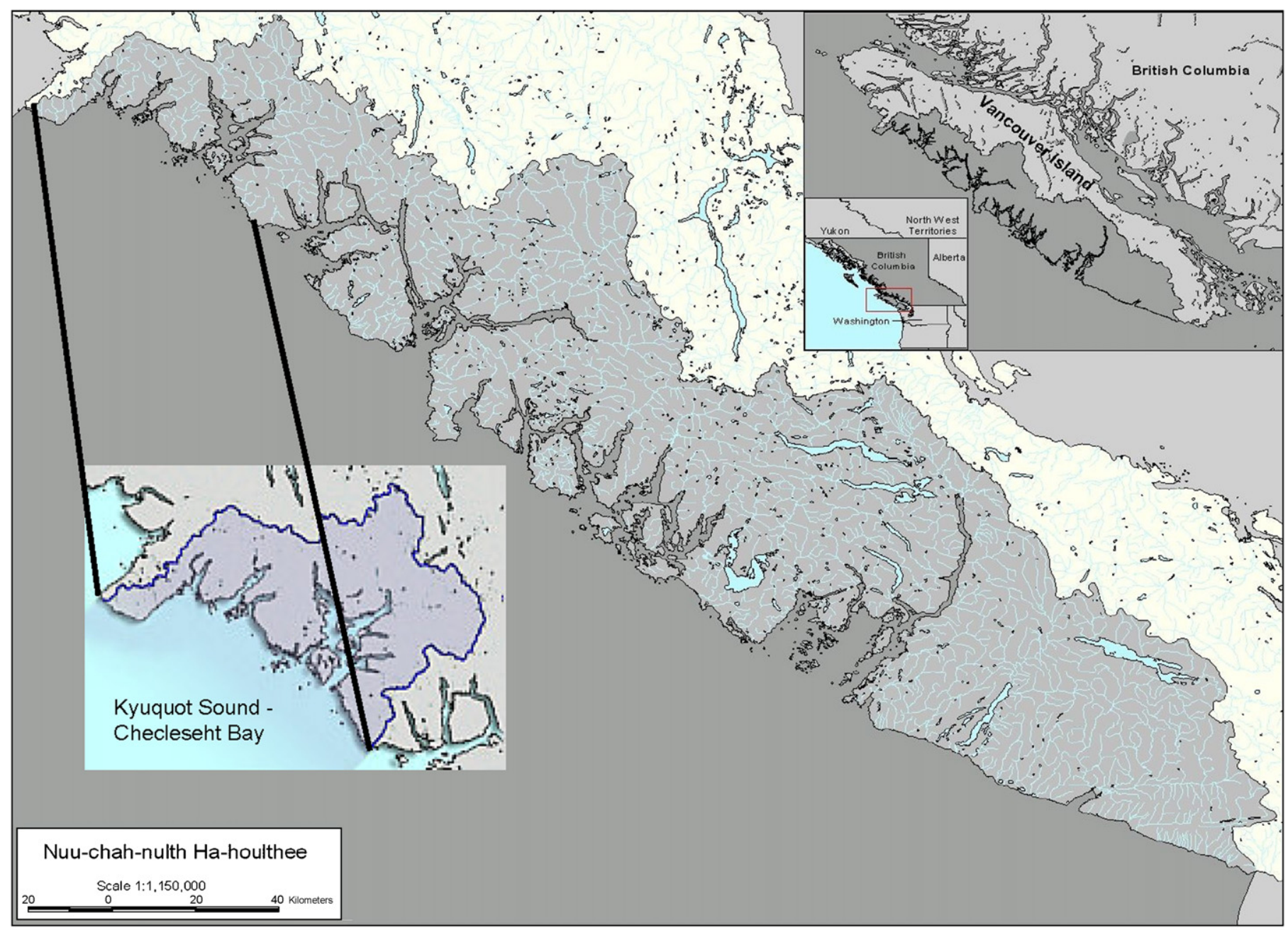

Source: WCVI Aquatic Management Board

Fig. 1. Kyuquot Sound-Checleseht Bay within Nuu-chah-nulth Territory (Ha-houlthee).

enrich, and raise additional interpretations of materials discussed in taped conversations with the second author over this three-year period. These involved not only a detailed review of events and some historical documents, but also iterative discussions of possible interpretations of events. The second author reviewed, commented on, and reinterpreted additional analyses produced by the first author. Band Council members and Nuu-chah-nulth fisheries staff reviewed the penultimate draft. Thus, reliability of evidence was achieved by several forms of triangulation [13]. Three graduate students (Alyssa Joyce, Katie Beach, and most notably Jennifer Silver) also contributed to various aspects of this fieldwork ${ }^{3}$

\section{(footnote continued)}

WCVI region by First Nations, commercial, recreational, and environmental interests, plus two Regional Districts, which had formed an organization to work together toward sustainable integrated aquatic management. See www.westcoastaquatic.ca

${ }^{3}$ See Beach's master's thesis on water quality testing in Kyuquot [14]. Silver's $\mathrm{PhD}$. thesis on clam markets is in progress.

\section{Background}

The second author's program, Kyuquot/Checleseht Fisheries (KCF), served Kyuquot, a community of some 200 permanent residents made up of members of the Kyuquot and Checleseht First Nations who were the original inhabitants of Kyuquot Sound and Checleseht Bay, and had laid claim to jurisdiction of this specific geographic area. As one united political entity, they formed the northernmost of the 14 First Nations which made up the Nuu-chah-nulth people who claim an area fronting $360 \mathrm{~km}$ of coastline of the west coast of Vancouver Island as their traditional territory (Fig. 1). ${ }^{4}$

This 18-year period was a time of intense political development by the Nuu-chah-nulth, who were among a few leaders in the development of the 1992 Canada-wide Aboriginal Fishing Strategy. ${ }^{5}$ One element of this Strategy

\footnotetext{
${ }^{4}$ The majority of Nuu-chah-nulth Nations are still negotiating a treaty with Canada and British Columbia.

${ }^{5}$ The Aboriginal Fishing Strategy emerged from constitutional negotiations, court decisions, new public opinion polls, and the Oka crisis, a
} 
was to develop local co-management between First Nations and the Department of Fisheries and Oceans (DFO), the federal agency whose mandate is to collect and analyze data, administer licenses, and regulate fishing and habitat protection. Two regional co-management boards eventually emerged on the west coast of Vancouver Island: the West Coast of Vancouver Island (WCVI) Clam Board in 1998 [15] and the WCVI Aquatic Management Board in 2002. The mandates of these regional multi-party boards did not directly include the type of local management discussed here, although both boards were intended to support this possibility.

Thus Kyuquot benefited from the leadership and resources of the NTC and its associated boards, especially its fisheries biologist who traveled to Kyuquot at regular intervals, and from policy and strategy discussions at Nuuchah-nulth headquarters in Port Alberni, to which Kyuquot band members traveled regularly, including the second author during the earlier stages of his career. In practice, however, the considerable expense and time requirements of travel to and from this remote area meant that Kyuquot had to be self-reliant most of the time. KCF received relatively little management attention and perceived that scarce funds were often better spent on local management efforts than on communication.

\section{Theoretical context: the resource and the community}

In order to appreciate the degree of difficulty or ease of establishing a legitimate local fisheries management system, consideration is first given to the key structural characteristics of the resource and the community which do or do not lend themselves well to this development. ${ }^{6}$

\subsection{Key characteristics of the resource}

Several characteristics of clams lend themselves well to local management. Clams are non-mobile and located in specific known areas (the relatively few productive beaches, which are much smaller than the entire territory). The size of the territory in which the beaches are located is relatively small so that all the beaches can be reached and monitored by boat. Harvesting activity is relatively visible, as harvesters must reach the beaches by boat, and so even if harvesters hide, their boats are visible. The boundary

\section{(footnote continued)}

major confrontation between an aboriginal group and the province of Quebec.

${ }^{6}$ Agrawal's [16] five-part framework is combined with one previously used [17] to characterize the nature of the resource management challenges and the conditions favouring co-management arrangements developed in Kyuquot. This framework involves (a) the nature of the resource, (b) the nature of the community, (c) the nature of the institutional/governance arrangements, (d) the nature of the senior government (co-managing) agency and (e) the nature of markets. Because the main interest here is in the historical development of (c) the arrangements for local management of the clam fishery, the other categories are used merely to provide context. Space restrictions do not allow consideration of (d) and (e). around the resource territory is clear and defendable, so that if unlicensed outsiders (not resident in Kyuquot, the only community in Kyuquot Sound/Checleseht Bay) come into the territory, their very presence can be questioned. Clams are culturally salient (important). All the foregoing characteristics make clam harvesting relatively easy to monitor, given sufficient resources (a seaworthy boat, fuel, and available staff). On the other hand, the non-spoilability and storability of clams is high and permits illegal "predigging". Clams can be dug before a legal harvest opening, held for weeks under water in a sack, and then delivered during a legal opening as if they had come from a different beach. This challenging characteristic, not previously identified in the literature, means that community support and reporting of pre-digging activity are necessary in order to achieve successful monitoring and enforcement of fishing regulations. In sum, five characteristics of clams lend themselves well to local monitoring/enforcement, while two characteristics make non-local management especially difficult.

\subsection{Key characteristics of the community}

Some characteristics of Kyuquot favor local management. The community is small, remote, isolated, located in the middle of a fairly large territory, and accessible only by sea and air, pre-disposing members to a high degree of interest in and identification with the resource. Because unemployment and underemployment varies seasonally from $30 \%$ to $40 \%$, the community is also dependent on the resource, especially in winter, when clam harvesting occurs and when other employment is at its lowest. Furthermore, a large number of local residents (62) hold commercial licenses to harvest clams, in addition to the constitutionally protected rights of all First Nations to harvest for food, social, and ceremonial purposes. The clam fishery is the only commercial fishery pursued as a family fishery by all ages and all genders: spouses often dig as a team as well as children and parents, youth and elders. The community thus has an unusually strong interest in and identification with the resource. ${ }^{7}$

All these features of place orientation, identification with the resource, and dependence are highly favorable to local management, but they are not the whole story. Dependence on the clam fishery has another face. There are virtually ${ }^{8}$ no other fishing licenses held by community members who

\footnotetext{
${ }^{7}$ Kyuquot is not a homogeneous community which can be assumed to have no internal disputes or important difference of opinion regarding management. Internal decision-making processes are required to represent some six major family groupings which formerly inhabited different village sites, and the two originally separate groupings of these, Kyuquot and Checleseht. The community is divided on how much authority in management decision should eventually be accorded the traditional chiefs and beachkeepers of each watershed, especially if these individuals do not live in the community. Despite these differences, many forces unite the community in the form of shared values, symbols, meaning, lifestyle, kinship, and commitment to community.

${ }^{8}$ Except for one salmon licence and one herring licence.
} 
only two decades ago were extremely active in the salmon, halibut, herring, and groundfish fisheries. Licenses were not lost due to incompetence, poor financial planning, or depressed stocks, but rather to government policies which resulted in province-wide patterns of license concentration into larger-scale vessels in urban areas and disproportionate loss of licenses in rural areas in the salmon fishery [18]. In the halibut fishery, licensing has become privatized in the form of individual transferable quotas, and no quotas are held in Nuu-chah-nulth territory except for a few which have been purchased by the Tribal Council recently. Furthermore, the growth of a lucrative sport fishery on salmon and halibut stocks in their area put former Kyuquot fishers in positions as guides and employees of fishing lodges where once they had been primary producers with direct access to the resource. This sport fishery is largely unregulated, as DFO has the capacity to come into the area only a few days a year, and KCF does not have the authority to board sport or commercial vessels or to detain a vessel if an illegal act is observed. Reporting of sport fishing violations by Kyuquot employees on sport vessels is inhibited by fear of job loss. In other words, the clam fishery is the only one which the Kyuquots, and the Nuu-chah-nulth feel is really theirs to manage in that it takes place entirely in their traditional territory; it includes few licensed outsiders; it has a high level of community participation; and it is the last remaining fishery in which they retain commercial licenses to any significant degree.

Not surprisingly, the situation of lost access to traditional fisheries creates anger and depression, particularly because outstanding aboriginal fishing rights and title issues were unresolved until late 2007 and have had little impact on clam management. ${ }^{9}$ These conditions in the community create challenges for the legitimacy of federal management, because the community perceives itself as an object of colonialism, and is not pre-disposed to view government regulations as fair or based on factual evidence. Government water quality studies, which began to close areas of Kyuquot Sound/Checleseht Bay to clam fishing in 1988, created extraordinary challenges for local management, which was in the position of enforcing water quality regulations which were perceived to have no legitimacy [19]. In sum, six out of eight community characteristics favored the creation of local management, but there were also unusual challenges because of past relationships with federal and provincial governments.

\footnotetext{
${ }^{9}$ The Nuu-chah-nulth launched a court case in 2005 against the federal government for loss of access to their traditional fisheries, a case which Kyuquot joined as an exception to their treaty negotiations. The largest Nuu-chah-nulth fishing community, Ahousaht (population c. 1,000), suffered some 50 suicide attempts in 2005 , an occurrence which many observers linked to the loss of fishing opportunity. Although five of the Nuu-chah-nulth First Nations signed a final agreement in 2007, nine did not.
}

\section{Characteristics of local governance arrangements: the importance of exclusion and internal regulation permitted under depuration}

The commercial fishery for Manila clams (Tapes philippinarum) in WCVI was quite small until the 1980s, but exceeded 800 metric tons by 1988 with a rise in prices and market demand, after which landings rapidly declined. DFO implemented area licensing in 1989 (the WCVI became Area F) and limited entry licensing in 1998 [15]. However, clam fisheries in Area F are still vulnerable to overfishing because all of the Area F clam license holders have the right to fish most of the WCVI. The Area F Clam Board sets the overall catch for each of the four sub-areas (of which Kyuquot Sound/Checleseht Bay is one) based on historical catch, and anecdotal discussion of abundance, but with little stock abundance data. In other words, Kyuquot as a sub-area had neither the right to exclude outsiders (other Area F licensees) nor the formal right to regulate the fishing of its own residents. The only mechanism used by the Clam Board to regulate is the number of days of harvesting (about 15-20 days a year in the last 10 years, distributed over the 3-4 day low tide days November-March), and the legal size limit of harvestable clams. Limiting the days does not guarantee that any particular beaches or areas will not be overharvested, however. It is desirable to leave some legal-sized (mature) clams on the beach in order to repopulate the beach more rapidly. Kyuquot/ Checleseht Fisheries (KCF) learned this lesson most painfully when they closed their own sub-area in 1989, based on their own survey's evidence of low abundance. When the fishery was re-opened in 1995, harvesters from all Area $\mathrm{F}$ descended on the area and in one or two seasons "wiped out all the gains in abundance of the 5-year closure". Thus lack of power to exclude is a major impediment to local management. The second major impediment is the lack of power to regulate the access of local residents. Ironically, shellfish closures because of water quality concerns became the source of a solution to both these problems.

Out of this overfishing crisis in the early 1990s, and out of the water quality closures which began in 1988 on a small scale and expanded in 1993, KCF (with the help of the Area F Clam Board) settled on a mechanism for excluding outsiders, regulating (limiting) the harvest of insiders, and keeping their two most productive beaches open to harvest: depuration. The governance arrangements listed in Table 1 and described in more detail below apply to the clam fishery during the period it was managed mostly as a depuration fishery 1999-2002. Depuration is a process in which clams from contaminated beaches are sold to a licensed processor who bathes the clams in tanks of flowing disinfected water for $48 \mathrm{~h}$, allowing them to purge themselves of harmful bacteria and viruses. A stock abundance survey must be done every two years and the local authority may regulate how many harvesters dig at 
Table 1

Management activities in all clam fisheries as performed by Kyuquot/Checleseht Fisheries (KCF), Department of Fisheries and Oceans (DFO), Environment Canada (EC), West Coast of Vancouver Island (WCVI) Clam Board (CB), Nuu-chah-nulth Tribal Council (NTC) fisheries biologist and the Canadian Food Inspection Agency (CFIA)

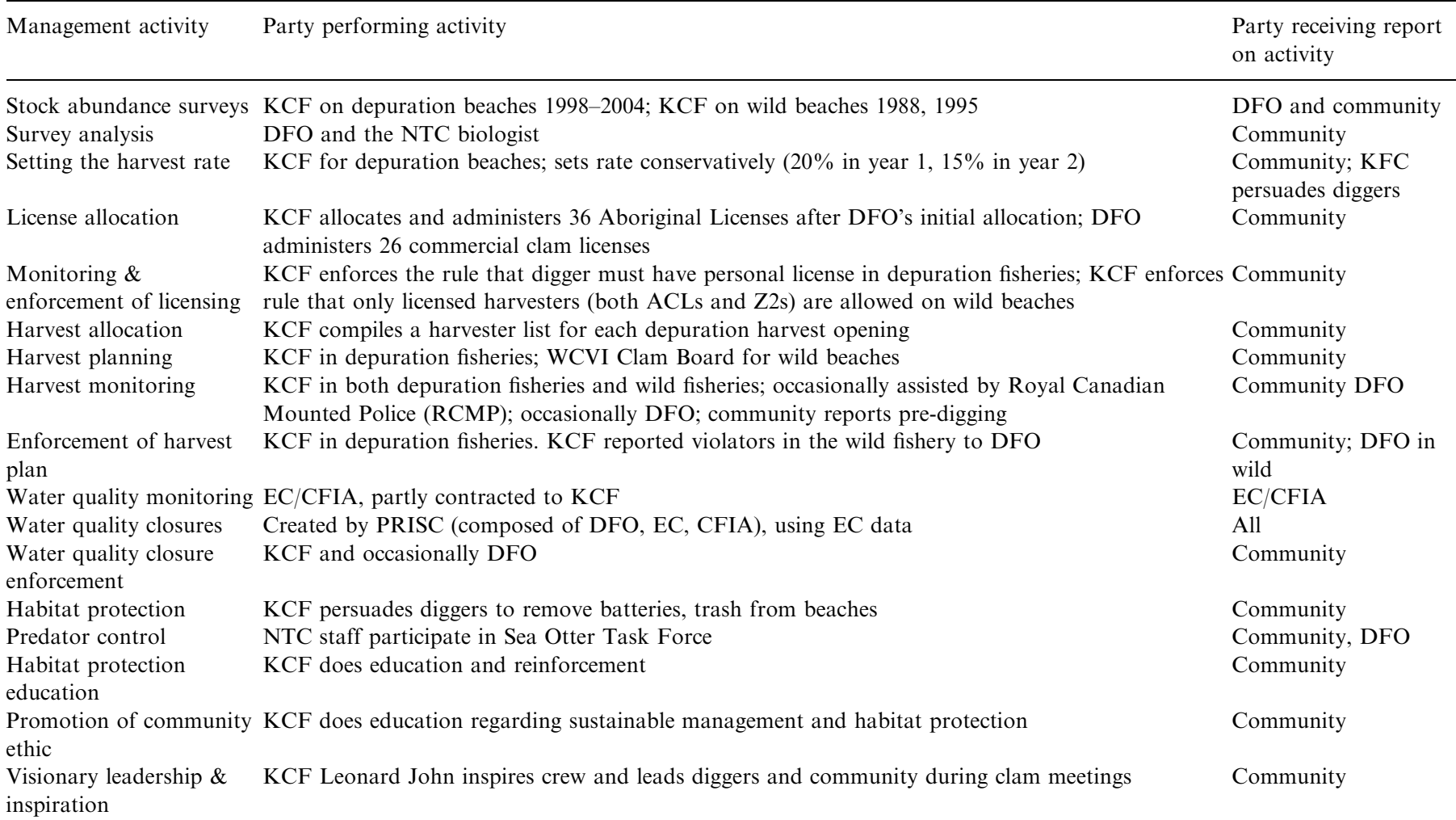

any one time. ${ }^{10}$ Thus depuration became a virtual mechanism for excluding outsiders, and regulating insiders.

Because depuration constituted a radical departure from the historical and more lucrative wild clam fishery (which continued to some extent alongside the depuration fisheries until it was closed by Environment Canada (EC) in 2004), willingness among Kyuquot diggers to support this mechanism developed only gradually. Table 1 lists the 17 management activities and all the parties involved in wild and depuration clam fisheries in Kyuquot. Of the 17 management activities in the clam fishery on depuration and wild beaches, KCF was involved in 14 . In 12 activities, KCF was the primary actor. These 12 activities, taken together, formed a system of informal local management embedded in a de facto co-management arrangement. $\mathrm{KCF}$ had the legal mandate to carry out only five of the activities (data collection, setting the harvest rate on depuration beaches, harvest monitoring, internal Aboriginal Clam License (ACL) allocation, internal harvest allocation on depuration beaches). However, if KCF had not monitored and reported to DFO violations on all beaches in licensing, digging on closed beaches, and pre-digging, the fishery

\footnotetext{
${ }^{10}$ Although Kyuquot was obligated to offer digging opportunity of $20 \%$ of its harvesting to other Area $\mathrm{F}$ licensees, no diggers from outside Kyuquot came to depuration fisheries, because only one beach was open at a time, and because clam prices under depuration were lower.
}

would have been virtually unmanaged and overfished. In other words, the fishery could not have functioned without the extremely active involvement of $\mathrm{KCF}$, despite the fact that they have no legal mandate to perform these management duties, and could not charge offenders (only report them).

\section{How a legitimate local management system developed}

Here the story is characterized dynamically as key roles played by various factors and as an interaction of factors at key moments. Four stages in the development of legitimacy are identified, each building on the previous stage: (1) a vision and local scientific and regulatory legitimacy are established, (2) the local authority gains political legitimacy, (3) the local authority gains regulatory capacity and moral legitimacy, (4) environmental values are revived. These developments must be viewed historically as a growth from little pre-existing local regulation or authority. When Leonard John arrived in Kyuquot in 1986, the community had no experience of regulation of a commercial clam fishery (which had previously been minimal as a commercial fishery) and when water quality closures began in 1988, virtually the entire community ignored them, and any other regulations, including licensing. In theory Kyuquot has chiefs with authority to be involved in such matters, but in practice the chiefs do not live in 
the community, and they had no capacity to make or enforce rules.

\subsection{Stage one: establishing a vision, scientific and regulatory legitimacy: 1986-1996}

Leonard John's career began with a 1986 visioning exercise that NTC biologist Bill Green conducted in Kyuquot, asking what future fishery was desired and what steps were necessary to achieve it. The inspiring personality, hopefulness, and vision of Green combined with John's idealism to sustain him through many challenges in the next two decades. It set the stage for his determination to bring the vision/long-term goal into being, and to believe in natural science as an ally. This direction led to actions through which KCF gained scientific legitimacy in the community.

In 1987-1988, John led the initiative to conduct stock assessments on key clam beaches, mobilizing a substantial community effort and obtaining the first clear scientific evidence about clam stock status. Through his educational efforts, the community voted by a large margin $(75 \%)$ that beaches had to be closed to recover from past overharvesting. The importance of this action should not be underestimated, as it indicated the existence of several conditions. (1) KCF and the community believed in the stock assessment science and were confident of their connection to it through the training of the NTC fisheries biologist and Leonard John; (2) KCF and the community were willing to contribute considerable volunteer effort to learn the status of their clam beaches; (3) the community was willing to forfeit immediate fishing opportunity for the benefit of protecting the future abundance of the stock. Through the democratically-supported action of closing the clam fishery, the community was willing to declare confidence in the science and legitimize the closure. They were taking leadership in the science, since at the time DFO did not have a clam stock assessment protocol in place. What is most important, however, is that the community was declaring publicly that their own values and process of deciding was consistent with an objective, scientific standard which was open to public and government scrutiny. Scientific legitimacy was thus based on objective standards, noted as key by Jentoft [20].

In addition to applying scientific rigor, John exerted rigorous regulatory authority through meticulous monitoring and enforcement of the four major government rules used to manage the clam fishery. (1) Diggers must hold a valid commercial license; (2) diggers must harvest only when there is a commercial harvest "opening" (no predigging); (3) diggers must not harvest on beaches which were closed due to water quality concerns; and (4) diggers must deliver real and legal-size clams to the clam buyers (vs. mud, gravel, and undersized clams). There was considerable community support for KCF's consistent enforcement of these government regulations, with the exception of the water quality closures. Because Kyuquot residents ate clams from beaches classified as contaminated and did not get sick, government closures of these beaches had low credibility. In its role as enforcer of these closures, $\mathrm{KCF}$ was viewed as being an arm of a colonial government. KCF practiced two strategies to maintain regulatory authority in these circumstances. It adopted a forgiving strategy when diggers were discovered at night on closed beaches: diggers were asked to leave and not return, and would not be reported if they did not repeat the offense. It reminded diggers that if government closures of contaminated beaches were not enforced, the entire area might be closed. In other words, diggers were reminded that it was in their self-interest to follow government regulations.

The community understood the need to establish regulatory authority and respected John's efforts, granting him a degree of regulatory legitimacy. They reported predigging activity, which could be observed when community members left during closed low tides carrying clam digging equipment. This decade 1986-1996 marked the first stage in the creation of respect for the capacity and capability of a local authority. But it was not sufficient in itself to produce a successful local management system because there was not full internal support for all the regulations. The local authority was still perceived by many as enforcing the rules of a colonial government, at least in the areas of licenses and water quality closures. However, there was still considerable respect for local authority simply for its ability to produce scientific evidence, to enforce rules in themselves, and thus maintain order. Furthermore, the local authority in its forgiving strategy was giving the message that it did not wish to punish, but simply to prevent illegal activity for the benefit of locals (the benefit being the prevention of a closure by government). In summary, stage one saw the development of scientific and regulatory legitimacy and some degree of management capacity.

\subsection{Stage two: the local authority gains political legitimacy: 1997-1998}

To this regulatory legitimacy was added local political legitimacy when KCF exerted its informal authority to defend local fishing interests in two key instances. One instance involved solving problems in local acquisition of a new category of clam license, the ACL, for which individuals were supposed to apply. When individuals did not apply by the deadline, John took the risk of filling out the applications himself for 36 community members who needed them and secured these licenses for them. When it became clear that these licenses would have been lost to the community without John's intervention, community members recognized him as capable of acting as a management authority in defense of their interests. In another instance, John was able to reinstate confiscated clam licenses from DFO, by showing that there had been a legitimate misunderstanding of a new water quality closure boundary, and that he, with the support of the Royal Canadian 
Mounted Police (RCMP) in the area, had only hours before monitored the harvest and considered it legitimate. Thus John garnered strong community approval for mobilizing legal support (the police), and for being able to use it to demonstrate to DFO that the community was indeed monitoring its own fishery in this case. KCF was perceived as being able to act effectively and decisively as a local authority which could protect community fishing rights. The political legitimacy it gained by these actions put it in a stronger position to assert regulatory authority.

\subsection{Stage three: the local authority gains regulatory capacity and moral legitimacy}

The gains of stage one and two were solidified and extended in stage three (1999-2002, the depuration fishery) as regulatory capacity was increased and as a democratic and effective local system of management was developed in a manner which won local moral authority for KCF. Regulatory capacity was first extended by opening greater communication with harvesters through individual visits after offenses. For example, a digger who had been evicted from a closed beach the night before would receive a sympathetic visit from John the next day in his home, and over a cup of coffee John would show respect for the person and explain how he saw his job, and why the regulation was important. Such visits assisted in diffusing the anger often directed at John in the form of threats and verbal abuse. Once the community (ACL) licenses had been won for the community, John used his authority over these licenses as a way of enforcing regulations by reminding fishers that they were a communal good, properly belonging to community members who were willing to respect the rules. If the violator's body language suggested acceptance of the regulations and willingness to comply in the future, the matter was left as a private conversation; the violator was spared public confrontation. If the violator displayed rudeness or resentment in the private visit, however, John would write a letter the next day, distributed to every household or at a public meeting, stating, in essence "You know and I know what you did, so stop it now or I'll revoke your privilege. You'll be put at the bottom of the waiting list for a license." The letter also emphasized the public trust he felt in protecting and honoring the communal licenses and the communal resource, clams. This approach accorded the maximum possible respect to fishers, and was a highly effective exercise of regulatory power (threat of loss of license), but because it was done in a traditional respectful manner which minimized shame and provided a graceful exit strategy to the offender, it also constituted an exercise of moral authority, as discussed below.

In 1997-1998, KCF held clam meetings which were increasingly well attended to discuss moving to depuration and even regulating how many harvesters could dig in any one tide. Depuration was a logical move at this point because Environment Canada's water quality closures became more extensive, and depuration provided a way to keep the two most productive beaches open to harvest, as well as to exclude most outsiders.

Under depuration, KCF had the authority for the first time to limit fishing effort on those beaches, which it did through equitable allocation mechanisms. Through community discussions, a lottery draw was developed to award digging opportunity to the first 15 harvesters to be drawn from a hat. They had exclusive harvesting privileges for the first low tide (3-4 days), to be replaced by the next 15 drawn on the following tide. The rules for how the lottery would be managed, for how family would be included after a first family member was drawn, etc. were developed through a number of democratic and high-communication avenues including clam meetings, individual meetings, circulation of suggested rules in advance of the meeting, and annual revisions of rules. KCF used additional mechanisms to hold harvesters accountable to the rules. Harvesters signed an agreement to abide by the rules, and signed a sheet affirming that they were present at the rule-making meeting. All these mechanisms served to minimize denial and back-tracking, and to raise respect for the agreements made at the clam meetings. In this way, the regulatory capacity of KCF was increased. Because the process was democratic, open, and responsive to digger suggestions, KCF gained internal moral legitimacy in addition to its increased regulatory legitimacy. Moral legitimacy means that a management system is consistent with the values of the social group, in this case the values of egalitarian allocation and openness of the democratic process. Systems which have moral legitimacy are believed by social scientists to be the most successful and enjoy the highest rates of compliance, as discussed below.

Scientific legitimacy was also increased during this period, by two methods. Fishing effort estimates became more sophisticated as the record of individual production patterns were established through the buyer verification process. Depuration digs occurred on only one beach at a time, enabling a tighter system of recording and checking the accuracy of each digger's product delivery to the buyer. At the same time, the stock surveys required every two years produced an accurate gage of the natural abundance of the beach and the impact of the diggers. In other words, both the standing stock and the harvest were being measured with far greater accuracy than had ever occurred historically. It was in the second year that John persuaded the diggers to adopt a precautionary approach by lowering the harvest rate to $15 \%$, and that he worked out a system of spatial rotation of digging areas in addition to the rotation of diggers. Diggers would only harvest one section of the beach at a time, and return to that section only after it had rested a few years. The NTC biologist described what happened as a result: "All the unproductive areas filled in and the beach became loaded with clams." By the third year of the depuration process, KCF realized that the management system had been very successful in increasing 
clam abundance on the beaches, especially the largest depuration beach, Malksope.

In summary, stage three was characterized by a further growth of scientific and regulatory authority, especially through the use for the first time of exclusion of outsiders and limitation of the number of insiders digging at one time on depuration beaches. In addition, beach area rotation was used, similar to fallow field rotation. These new regulatory mechanisms taken together allowed $\mathrm{KCF}$ to achieve a high level of moral legitimacy. It has not been sufficiently recognized that management systems run on moral authority perform at a much higher level than those run on legal, political, scientific, or regulatory authority alone. To have complete legitimacy, a system must be justified according to moral principles and values which underpin the rational, legalistic, logistical, and scientific grounds for management [20]. We summarize below how the system met a number of criteria for moral legitimacy that are broadly accepted by social scientists.

(1) There were objective standards in the system, regardless of the users' subjective views [21]. Objective standards were evident in the stock assessment used to determine the sustainable harvest level (natural science), the process by which access was allocated (lottery), the process by which regulations governing the harvest were made (community meetings), the process through which the harvest regulations were effectively and fairly enforced (no favoritism), and the process by which priorities and decision-making about the fishery were made (community meetings, one-on-one discussions with $\mathrm{KCF}$ ).

(2) The standards were visible, transparent, and culturally appropriate to the community and thus meet the standard of "ideal normative agreement" which sociologist David Held, following Max Weber [20], considered the only regulatory communicative process that is free of domination (as contrasted with coercion, tradition, apathy, pragmatic acquiescence, instrumental acceptance, normative agreement). The exceptions here were the federal water quality standards enforced by the KCF, which fall into the category of "instrumental acceptance". The strength of the moral legitimacy of the KCF in stage 3 can be measured by the fact that it was not hurt for enforcing unpopular regulations with low legitimacy, because its moral legitimacy was so high where it did apply visible and objective standards. Jentoft [20] proposed that a good test of a legitimate system is whether users support it even when it disadvantages them. Two fishers who disobeyed regulations, one of whom gleefully acknowledged this, still showed respect for the KCF and the system, even while making it clear that they would take individual advantage when they could. Much of the literature on procedural justice emphasizes that trust in leaders and authorities is based more on the perceived fairness of the means used to make decisions, and their consistency with prevailing moral and ethical standards [22] than on the fairness of the outcomes of those decisions [23]. The implication of this definition is that individuals will react positively to a decision, even if it is not in their favor, as long as they perceive the procedures used to arrive at that decision to be fair, and particularly if they have the opportunity to have a "voice" in the design of the process [24]. Likewise, Schumann [7] showed that development of "consciousness" about conservation among Chilean fishers did not come from individual success, but rather from the sense of working together successfully in a group. Schumann's finding, and this case, supports Jentoft's idea that individual outcomes are less important than the perception that the system as a whole is being run fairly.

(3) The outcomes were effective and fair. Tyler [12] and Greenberg and Tyler [22], however, emphasized the importance of actual results in addition to fair process as a measure of legitimacy. The system was effective in delivering a good result, as discussed above under "regulatory legitimacy". The KCF was perceived as knowing how to do its job well, and implementing the regulation effectively, catching offenders, being vigilant.

(4) The role of scientific legitimacy. Social scientists are divided on the question of the role of natural science in creating legitimate regulations, since natural scientists have been blamed for "getting it wrong" in many fishing crises and have often ignored important local knowledge [8]. However, this case demonstrates, in conjunction with others $[7,9,10]$, that the use of natural science in the context of a cooperative and highly communicative relationship plays a key role in legitimacy creation. In this case, scientific legitimacy played a key role both in stage one and in stage three.

\subsection{Stage four: revival of environmental values and the creation of new values}

The establishing of the management system's moral authority allowed the re-emergence and expression of values and attitudes which had existed from the beginning, but which had had no platform for some time. These became more expressed internally and publicly as diggers developed confidence they could regulate this fishery, and command respect for the scientific, regulatory, political, and moral authority of their management system. In stage three the KCF had emphasized picking up garbage on the beach, especially batteries from diggers' headlamps which would corrode and damage the beach and clams if abandoned. Emphasis was also put on not disturbing the food chain, replacing rocks and logs if these were moved during digging, so that barnacles and micro-habitats would remain in place. Care had to taken that engine propellers did not dig up the sand when a boat landed, and that oil was not spilled on the beach. Concerns about protecting 
and not disturbing ecosystem functions were part of the traditional Nuu-chah-nulth understanding of the natural world that "everything is one".

In stage four, more diggers voluntarily did these activities, also picking up garbage left by other diggers, and reported to KCF that they had done this. They had begun to take responsibility for taking care of the resource in a way which showed forethought about the health of the beach, and a concern for stewarding the resource.

\section{Conclusions}

The purpose of exploring an 18-year legitimacy-building process in one fishery in one community was to show that legitimacy is complex, multi-faceted, and developed progressively as components evolve. Regulatory, scientific, political, and moral components of legitimacy tend to interact and be mutually reinforcing, as was the case particularly with regulatory and scientific components, and with political and moral components. The historical "worst case scenario" of widespread poaching and disregard for regulations in 1986 allowed a clearer analysis of how a highly successful system was built over time.

Structural characteristics of the resource and the community lent themselves well to local regulation and the creation of local legitimacy: seven out of nine important resource characteristics could be seen as favorable to local management, while six out of eight community characteristics were also favorable. Consistent with the common property and co-management literature, we consider that the more such structural characteristics exist as pre-conditions, the stronger is the foundation for legitimacy creation. Furthermore, the local authority was able to exercise de facto power in $12-14$ of the 17 activities in clam management.

However, this analysis points to the fact that these structural conditions are insufficient in themselves to create an effective regulatory system, and that an examination of these characteristics needs to be integrated into a dynamic account of how legitimacy is built. The historical account of the stages of building legitimacy illustrated how each stage built upon the preceding one, and appeared to be a pre-condition for it. After examining four stages in the creation of legitimacy, it is possible to generate the following hypotheses about some of the key conditions for and dynamics of creating legitimate fishing regulations and a legitimate local management authority.

1. This case lends support to the hypothesis of several others that the sharing of ecological knowledge by natural scientists plays a key role in legitimizing regulations. It does not appear to matter if the scientist works for government, is a consultant, or a local manager applying scientific methods. What matters is that the science is communicated effectively and that time is taken to teach and discuss it respectfully with fishers.
2. This discussion leads to the hypothesis that regulatory legitimacy is a key dimension of and building block in legitimacy creation, to the extent that the local authority can demonstrate effectiveness in implementing regulations (including those of the state), and keeping the system functional, orderly, and acceptable to the state so that closures are not threatened, and to the extent that a moderate level of involvement by fishers can be maintained. The twice yearly well-attended clam meetings as a venue for creating and revising regulations is a good example of a "middle ground" level of involvement of fishers in regulation [20], a level that is not too overwhelming in its demands or details. Fishers were happy to make basic regulatory policy decisions based on information presented at these meetings, and sign onto specific details about allocation of opportunity, partially because the local authority was perceived as an effective regulator and partially because the regulations were perceived as fair and sensible.

3. This discussion leads to the hypothesis that political legitimacy is an important dimension of legitimacy creation, in that the local authority is perceived as an effective defender of local fishing rights, willing and able to stand up to external authority when necessary.

4. This discussion leads to the hypothesis that scientific and regulatory legitimacy are forms of legitimacy that apply at the "instrumental acceptance" level in David Held/Max Weber's hierarchy of factors that produce compliance. In other words, fishers follow regulations because it helps them achieve their own goals, whether they believe in the regulations or not. Political legitimacy, on the other hand, appears to operate at the level of "normative agreement" in that local fishers respect the power and initiative of the local authority in defending them against actions by the state.

5. This discussion leads to the hypothesis that moral legitimacy is the most important form of legitimacy, operating at the "ideal normative agreement" level, and based on fishers' perceptions that the regulations are fair, democratically made, transparent, inclusive, and produce good outcomes.

6. This discussion leads to the hypothesis that scientific, regulatory, and political forms of legitimacy precede and support the creation of moral legitimacy, and are necessary for its emergence. Therefore, the order in which various forms of authority are exerted is important. Moral legitimacy could only develop after scientific, regulatory, and political legitimacy were in place. The latter three may be seen as the building blocks for the development of a local management system, which cannot have substantial strength until it also has moral legitimacy, and therefore is adopted as part of the value system of the local community.

7. These findings support the finding of Schumann [7] that it is management and not ownership that leads to stewardship. While the discussion has not dealt with individual transferable quotas, it has considered a 
situation in which First Nations assert ownership, but became stewards when they had build an effective and legitimate management system.

8. These findings support those of others who state that it is necessary to go beyond asking how regulations are perceived by fishers if the goal is to learn how to make effective regulations while lowering the cost of monitoring and enforcement. It is necessary to also consider the legitimacy of the management authority and the legitimacy of the management system in its process and outcomes.

Finally, an important finding of this discussion is that a local management system based on the mechanisms described above can be highly effective, and certainly far more effective than a government system working alone. Senior governments do not have the capacity to enforce their regulations, or to devise ones which could work in remote areas. In such remote situations, government acceptance of local management should be based on an awareness that the alternative is - without a local authority - substantial poaching and overexploitation. Senior governments needs to recognize the great value of multidimensional local legitimacy in achieving sustainable management of a resource which has not yet been successfully managed by conventional means.

\section{Acknowledgements}

The authors thank the Social Sciences and Humanities Research Council of Canada for supporting this research financially, the West Coast Vancouver Island Aquatic Management Board and the West Coast Vancouver Island Clam Board for supporting it morally, the Council, Staff, Clam Co-Management Committee, and residents of Kyuquot for all their helpfulness, patience, and good will, the Nuu-chah-nulth Tribal Council Fisheries staff for their good ideas, and Randy Webb of DFO and Jayde Tyres of Environment Canada for their cooperation and helpfulness. They specially thank Kevin Head for all his help and Natalie Jack for her generous heart and warm hospitality.

\section{References}

[1] deYoung B, Peterman RM, Dobell AR, Pinkerton E, Breton Y, Charles AT, Fogarty MJ, Munro GR, Taggart C. Canadian marine fisheries in a changing and uncertain world. Canadian Special Publication of Fisheries and Aquatic Sciences. No. 129; 1999.; Charles A. Sustainable fishery systems. Oxford: Blackwell Science; 2001.

[2] Castilla JC, Defeo O. Paradigm shifts needed for world fisheries. Science 2005;309:1324-5;

Defeo O, Castilla JC. More than one bag for the world fishery crisis and keys for co-management successes in selected artisanal Latin American shellfisheries. Reviews in Fish Biology and Fisheries 2005;15:265-83.

[3] Organization for Economic Co-operation and Development. Towards sustainable fisheries: economic aspects of the management of living marine resources. Paris: Organization for Economic Cooperation and Development; 1997;

Hatcher A, Jaffry S, Thebaud O, Bennet E. Normative and social influences affecting compliance with fishery regulations. Land Economics 2000;76(3):448-61;

Tietenberg $T$. The tradable permits approach to protecting the commons: what have we learned? In: Ostrom E, Dietz T, Dolsak N, Stern PC, Stonich S, Weber EU, editors. The drama of the commons. Washington, DC: National Research Council; 2000. p. 197-232;

Symes D, Steins N, Alegret JL. Experiences with fisheries comanagement in Europe. In: Wilson D, Nielsen JR, Degnbol P, editors. The fisheries co-management experience: accomplishments, challenges, and prospects. Boston: Kluwer; 2003. p. 119-34.

[4] Goldfarb RS, Griffith WB. Amending the economist's 'rational egotist' model to include moral values and norms. Part 2: alternative solutions. In: Koford KJ, Miller JB, editors. Social norms and economic institutions. Ann Arbor: University of Michigan Press; 1991;

Hausman DM, MacPherson MS. Taking ethics seriously: economics and contemporary moral philosophy. Journal of Economic Literature 1993;31:671-731.

[5] Austin WG. Justice in intergroup conflict. In: Worchel S, Austin WG, editors. Psychology of intergroup relations. Chicago: Nelson-Hall Publishers; 1986. p. 153-75;

Jentoft S. Fisheries co-management: delegating government responsibility to fishermen's organizations.Marine Policy. In: Pinkerton EW, editor. Co-operative management of local fisheries: new directions in improved management and community development. Vancouver: University of British Columbia Press; 1989. p. 137-54; Jentoft S. Legitimacy and disappointment in fisheries management. Marine Policy 2000;24:141-8;

Wilson D, McCay BJ. How the participants talk about "participation" in mid-Atlantic fisheries management. Ocean and Coastal Management 1998:41-61.

[6] Foucault M. Discipline and punish: the birth of the prison. New York: Random House; 1995. [1975].

[7] Schumann S. Co-management and "consciousness": fishers' assimilation of management principles in Chile. Marine Policy 2007;31:101-11.

[8] Soto CG. Social-cultural barriers to applying fishers' knowledge in fisheries management: an evaluation of literature cases. School of Resource and Environmental Management. Burnaby, BC: Simon Fraser University. Ph.D. Dissertation, 2006. 〈http://www.rem.sfu. ca/pubs.htm >

[9] Gendron L, Camirand R, Archambault J. Knowledge-sharing between fishers and scientists: towards a better understanding of the status of lobster stocks in the Magdalen Islands. In: Neis B, Felt LF, editors. Finding our sea legs: linking fishery people and their knowledge with science and management. St. Johns: Institute of Social and Economic Research. Memorial University; 2000. p. 56-71.

[10] Zwanengburg K, King P, Fanning P. Fishermen and scientists research society: a model for incorporating fishers and their knowledge into stock assessment. In: Neis B, Felt LF, editors. Finding our sea legs: linking fishery people and their knowledge with science and management. St. Johns: Institute of Social and Economic Research Memorial University; 2000. p. 124-32.

[11] Christy Jr FT. Territorial use rights in marine 1982 fisheries: definitions and conditions. FAO Fisheries Technical Paper 1982:227.

[12] Tyler TR. Why People Obey the Law. New Haven: Yale University Press; 1990.

[13] Yin RK. Case study research: design and methods. Thousand Oaks: Sage Publications; 2003.

[14] Beach K. Collaborative investigations of water quality pollution patterns: working with the Kyuquot/Checleseht First Nations in British Columbia. M.R.M. research project no. 411, School of Resource and Environmental Management. Burnaby, BC: Simon Fraser University, 2006. 〈http://www.rem.sfu.ca/pubs.htm〉

[15] Dunlop R. Area F intertidal clam fishery community management board: emerging community-based management in Nuu-chah-nulth 
Ha'houlthee on the West Coast of Vancouver Island. Bulletin of the Aquacultural Association of Canada 2000;100:30-6.

[16] Agrawal A. Common resources and institutional sustainability. In: Ostrom E, Dietz T, Dolsak N, Stern PC, Stonich S, Weber EU, editors. The drama of the commons. Washington, DC: National Research Council; 2000. p. 41-86.

[17] Pinkerton E, Weinstein M. Fisheries that work. Sustainability through community-based management. Vancouver, BC: David Suzuki Foundation; 1995.

[18] Hayward B. The BC salmon fishery: a consideration of the effects of licensing. B C Studies 1981;50:39-51;

Edwards DN, Scholz A, Tamm EE, Steinback C. The catch-22 of licensing policy: socio-economic impacts in British Columbia's commercial ocean fisheries. p. 65-76. In: Sumaila UR, Marsden AD., editor. North American Association of Fisheries Economists Forum Proceedings. Fisheries Centre Research Reports 14(1). Vancouver, Canada: Fisheries Centre, the University of British Columbia; 2005.

[19] Beach K, Pinkerton E. The challenges of designing a transparent research project integrating First Nation's knowledge and natural science. In: Walsh D, Malcolm C, Metuzals K, editors. Managing for sustainability in Canadian waters. St. Johns: Institute of Social and Economic Research; 2007 [under review].

[20] Jentoft S. Legitimacy and disappointment in fisheries management. Marine Policy 2000;24:141-8.

[21] Tyler TR. Why people obey the law. New Haven: Yale University Press; 1990;

Beetham D. The legitimation of power. Atlantic Highlands, NJ: Humanities Press International; 1991;

Jentoft S. Legitimacy and disappointment in fisheries management. Marine Policy 2000;24:141-8.

[22] Greenberg J, Tyler TR. Why procedural justice in organizations? Social Justice Research 1987;1(2):127-41.

[23] Lander MC, Purvis RL, McCray GE, Leigh W. Trust-building mechanisms utilized in outsourced IS development projects: a case study. Information and Management 2004;41:509-28.

[24] Alexander S, Ruderman M. The role of procedural and distributive justice in organizational behavior. Social Justice Research 1987;1(2): 177-97. 